\title{
Relationship Between High Sensitivity C-reactive Protein and CagA Positive Helicobacter pylori in Cardiac Syndrome X
}

\author{
Y. Rasmi ${ }^{1,2^{*}}$, M. H. Seyyed-Mohammadzad ${ }^{3}$, and S. Raeisi ${ }^{2}$ \\ ${ }^{1}$ Cellular and Molecular Research Center, Urmia University of Medical Sciences, Urmia, Iran \\ ${ }^{2}$ Department of Biochemistry, Faculty of Medicine, Urmia University of Medical Sciences, Urmia, \\ Iran \\ ${ }^{3}$ Department of Cardiology, Faculty of Medicine, Urmia University of Medical Sciences, Urmia, \\ Iran
}

Received 17 March 2013, accepted in final revised form 3 July 2013

\begin{abstract}
Cytotoxin-associated gene A ( $\mathrm{CagA}$ ) may induce a persistent systemic inflammatory response in cardiac syndrome $\mathrm{X}$ (CSX). We aimed to evaluate relationship of CagA status and high sensitivity C-reactive protein (hs-CRP) in CSX patients. Sixty CSX patients and 60 gender matched controls were enrolled. Plasma samples were tested in terms of the presence of IgG antibody to Helicobacterpylori (anti-H. pylori) and CagA (anti-CagA) using ELISA method. Also, plasma level of hs-CRP was measured by ELISA method. CSX patients were detected to have significantly higher plasma hs-CRP level in comparison with the control ones $(3.64 \pm 3.07 v s .0 .54 \pm 0.49, \mu \mathrm{g} / \mathrm{ml}, P=0.0001)$. Plasma levels of hs-CRP in CSX patients with anti-CagA+ were significantly higher than those in anti-CagA(-) (CSX: $4.66 \pm 3.63 v$ s. $2.58 \pm 1.95 \mu \mathrm{g} / \mathrm{ml}, P=0.011$ ). Also, plasma levels of hs-CRP in the controls with anti-CagA+ were significantly higher than those in anti-CagA- $(1.05 \pm 0.68 v s$. $0.32 \pm 0.31 \mu \mathrm{g} / \mathrm{ml}$, respectively, $P=0.004)$. The present data suggested that CagA status was probably associated with susceptibility to severe CSX by causing inflammation. The evidence for this hypothesis indicated that levels of hs-CRP increased in anti-CagA+ patients compared to the anti-CagA- ones.
\end{abstract}

Keywords: Cardiac syndrome X; Helicobacter pylori; Inflammation ; hs-CRP, Cytotoxinassociated gene A.

(c) 2013 JSR Publications. ISSN: 2070-0237 (Print); 2070-0245 (Online). All rights reserved. doi: http://dx.doi.org/10.3329/jsr.v5i3.14171 J. Sci. Res. 5 (3), 527-533 (2013)

\section{Introduction}

Cardiac syndrome $\mathrm{X}(\mathrm{CSX})$ is a condition characterized by the presence of angina pectoris and a positive response to stress or radionuclide tests with a normal coronary arteriogram [1]. Coronary endothelial dysfunction leading to microvascular angina has been proposed

${ }^{*}$ Corresponding author: rasmiy@umsu.ac.ir 
as the most important pathogenetic mechanism in this syndrome [2]. The mechanisms responsible for endothelial dysfunction in CSX patients are not well understood [3]; but, recent observations have revealed the role of inflammation in pathogenesis of endothelial dysfunction [4] and correlation of C-reactive protein (CRP) concentration with severity of symptoms in CSX patients [5].

CRP, the most exquisitely sensitive systemic marker of inflammation, has been recently known to be associated with vascular dysfunction [6]. The most important one among possible candidates for a clinically useful biomarker of cardiovascular disease risk is CRP as measured by high-sensitivity assay [7].

On the other hand, systemic inflammation that can be caused by Helicobacter pylori (H. pylori) may play an important pathogenic role in vascular diseases such as cardiac syndrome $\mathrm{X}$ (CSX) [8]. H. pylori is a gram-negative bacterium which infects human stomach. It may also lead to extra-intestinal manifestations such as vascular and heart diseases [9] by causing systemic inflammation [10].

Several studies have demonstrated that only cytotoxin associated gene A positive $(\mathrm{Cag} \mathrm{A}+)$ strain of $H$. pylori could increase risk of atherosclerosis, except CagA negative H. pylori (anti-CagA-). CagA+ may evoke more inflammation and it has been identified as a possible marker of $H$. pylori virulence [11-13]. Therefore, this study sought to analyze possible relationship between CagA+ strain and hs-CRP level in CSX patients.

\section{Experimental}

\subsection{Study design}

This study was a case-control one, conducted in the Department of Cardiology, Urmia University of Medical Sciences, Urmia, Iran. The patients with CSX and apparently healthy controls were studied. The case group consisted of 60 consecutive CSX patients ( 38 females, 22 males; mean age of $51.8 \pm 12.3$ years).

Entry criteria included typical anginal chest pain, normal 12-lead ECGs at rest, positive exercise ECG stress test response and completely normal coronary angiogram. Non-cardiac causes of chest pain such as gastrointestinal and musculoskeletal disorders and diabetes mellitus were also identified and ruled out as appropriate. The control group consisted of 60 apparently healthy subjects (39 females, 21 males; mean age of $48.9 \pm 6.3$ years). None of the control subjects had previous history of chest pain or acute/chronic diseases. Also, none of these subjects were taking cardiac or non-cardiac medications. The study was approved by the local research ethics committee and a written informed consent was obtained from all the subjects.

\subsection{Biochemical assays}

A 5-mL trisodium citrated blood sample was obtained from each subject and centrifuged at $2,000 \mathrm{~g}$ for $15 \mathrm{~min}$. Plasma was aliquoted and stored at $-80^{\circ} \mathrm{C}$ until the analysis. Specific anti-H. pylori immunoglobulin-G concentration was measured by a commercial 
enzyme-linked immunosorbent assay (ELISA; Glob anti- H. pylori/IgG, Milan, Italy) according to its manufacturer's instructions (sensitivity of $96.5 \%$ and specificity of 98.6\%). Plasma positivity to the specific virulence-associated H. pylori antigen CagA was assessed by ELISA (Dia.Pro, Milan, Italy; sensitivity and specificity of >98\%) in $H$. pylori + , as well. Also, plasma levels of hs-CRP were determined using ELISA kits from Monobind Inc. (Lake Forest, California, USA).

\subsection{Statistical analysis}

The data were analyzed in SPSS software (v. 16.0). Qualitative variables (prevalence of H. pylori and CagA+ infections) were shown as absolute values and percentage and quantitative variables (age, systolic blood pressure, diastolic blood pressure and body mass index (BMI)) and level of hs-CRP were demonstrated as mean \pm standard deviation (SD). Differences between the groups and subgroups were interpreted based on independent-samples $t$-test and, for qualitative data, it was on the basis of Chi-square test. $P$ value of less than 0.05 was considered statistically significant.

\section{Results}

Sixty CSX patients (38 females and 22 males) with mean age of $51.8 \pm 12.3$ years were compared with 60 healthy individuals (39 females and 21 males) with mean age of $48.9 \pm$ 6.3 years in the control group. Demographic and clinical characteristics of both groups are depicted in Table 1. There were no significant differences in terms of age, gender, systolic and diastolic blood pressures and BMI between CSX and control groups $(P>0.05)$.

Table 1. Demographic and clinical characteristics of CSX patients and controls.

\begin{tabular}{lccc}
\hline Variables & CSX & Control & $P$ value \\
\hline Age (years) & $51.8 \pm 12.3$ & $48.9 \pm 6.3$ & 0.096 \\
Gender (female/male) & $38 / 22$ & $39 / 21$ & 0.851 \\
Systolic BP $(\mathrm{mmHg})$ & $122.5 \pm 9.3$ & $120.2 \pm 7.0$ & 0.127 \\
Diastolic BP $(\mathrm{mmHg})$ & $77.6 \pm 8.5$ & $75.8 \pm 6.9$ & 0.201 \\
BMI $\left(\mathrm{kg} / \mathrm{m}^{2}\right)$ & $27.0 \pm 4.2$ & $26.2 \pm 3.4$ & 0.301 \\
\hline
\end{tabular}

BP: blood pressure; BMI: body mass index

H. pylori infection was diagnosed in 57 (95.0\%) patients with CSX and $24(40.0 \%)$ individuals in the control group $(P<0.01)$. Also, among CSX group, 31 patients had positive CagA (54.4\% of $H$. pylorit) while only 13 ones had CagA+ $(54.2 \%$ of $H$. pylori,$+ P>0.05)$ in the control group. 
Levels of hs-CRP were measured and compared between CSX and control groups. As presented in Fig. 1, the patients with CSX were detected to have significantly higher plasma levels of hs-CRP in comparison to the control group (3.64 \pm 3.07 vs. $0.54 \pm 0.49$, $\mu \mathrm{g} / \mathrm{ml} ; P=0.0001)$.

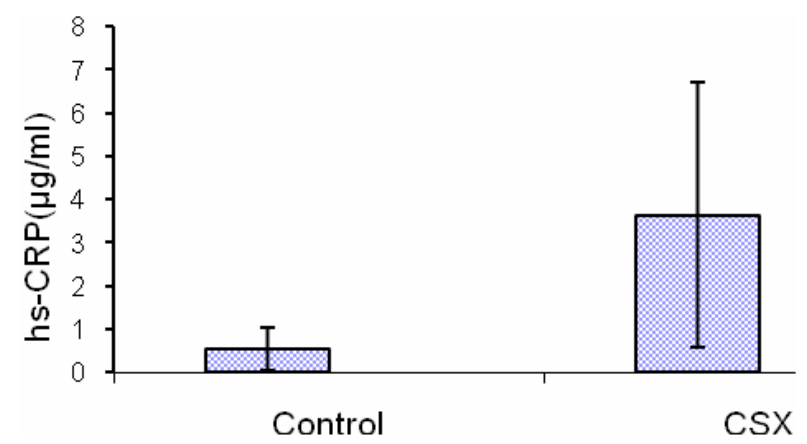

Fig. 1. The plasma levels of hs-CRP in CSX patients and controls.

Also, in CSX and control groups, levels of hs-CRP were compared between anti- $H$. pylori+/ anti-H. pylori- and anti-CagAt/anti-CagA- subgroups. As presented in Table 2, in both groups, plasma levels of hs-CRP in anti-H. pylori+ subgroup [CSX: 3.71 3.14 ; control: $0.72 \pm 0.65 \mu \mathrm{g} / \mathrm{ml}$ ] were higher than those in anti-H. pylori- subgroups [CSX: 2.40 \pm 0.81 ; control: $0.42 \pm 0.30 \mu \mathrm{g} / \mathrm{ml},(P=$ not available and $P=0.021$, respectively). Regarding the low number of CSX patients by anti-H. pylori- (5\%: three of the samples were anti-H. pylori-), $P$-value was not statistically valuable for anti- $H$. pylori status in CSX patients.

Table 2. The levels of hs-CRP in Anti-H. pylori+, Anti-H. pylori-, Anti-CagA+ and Anti-CagAsubgroups of CSX patients and controls.

\begin{tabular}{lllrrrc}
\hline Group & $\begin{array}{l}\text { Anti- } H . \\
\text { pylori+ }\end{array}$ & $\begin{array}{l}\text { Anti- } H . \\
\text { pylori- }\end{array}$ & $P$ & Anti-CagA+ & Anti-CagA- & $P$ \\
\hline Controls & $0.72 \pm 0.65$ & $0.42 \pm 0.30$ & 0.021 & $1.05 \pm 0.08$ & $0.32 \pm 0.31$ & 0.004 \\
CSX & $3.71 \pm 3.14$ & $2.40 \pm 0.81$ & NA & $4.66 \pm 3.63$ & $2.58 \pm 1.95$ & 0.011 \\
\hline
\end{tabular}

In addition, as shown in Table 2, in both groups, plasma levels of hs-CRP in antiCagA+ subgroups [CSX: $4.66 \pm 3.63 \mu \mathrm{g} / \mathrm{ml}$; control: $1.05 \pm 0.68 \mu \mathrm{g} / \mathrm{ml}$ )] were significantly higher than those in anti-CagA- subgroups [CSX: $2.58 \pm 1.95$; control: $0.32 \pm 0.31 \mu \mathrm{g} / \mathrm{ml}$ ], $(P=0.011$ and $P=0.004$, respectively). 
On the other hand, we made a correlation gender wise and anti-CagA status (positive or negative). We found anti-CagA (-)_CSX-females were significantly higher than CSXfemales in anti-CagA(-) subgroups $(P=0.031)$ (see Table 3$)$.

Table 3. Correlation between gender and anti-CagA status in CSX patients and controls.

\begin{tabular}{lccc}
\hline Gender (female/male) & Anti-CagA+ & Anti-CagA- & $P^{*}$ \\
\hline Controls & $9 / 4$ & $6 / 5$ & 0.459 \\
CSX & $24 / 7$ & $13 / 13$ & 0.031 \\
\hline
\end{tabular}

$P^{*}=$ pearson correlation.

\section{Discussion}

It has been recently found that $H$. pylori is associated with CSX [14]. This organism may cause inflammation and immune response by releasing some cytotoxic substances which are mainly responsible for systemic manifestations of $H$. pylori [15]. Numerous pieces of evidence have shown that inflammation plays a key role in cardiovascular diseases [1618]. Tondi et al. showed a significant role for subclinical inflammation in the impairment of endothelium-dependent vasodilator function of these patients [19].

CRP is a sensitive, nonspecific systemic marker of inflammation [20]. Although CRP was initially believed to be only a marker of vascular inflammation, recent research have indicated that it also plays an active role in atherogenesis [7]. Calabro et al. [21] demonstrated that smooth muscle cells of human coronary arteries may also produce CRP as a local response to inflammatory cytokines. They further noted that this locally produced CRP may participate in the atherogenic process [21]. Compared to controls, patients with CSX had significantly higher hs-CRP concentrations [22].

In addition, some recent studies have indicated that high levels of CRP are associated with coronary microvascular endothelial dysfunction in CSX [3]. Recio-Mayoral et al. [23] suggested a role for inflammation in the modulation of coronary microvascular responses in CSX patients.

Arroyo-Espliguero et al. conducted a study in which it was shown that CRP concentrations are correlated with intima-media thickness of the common carotid artery in CSX patients; this issue confirmed the presence of an impaired arterial wall structure and some degrees of atherosclerotic burden in these patients despite normal findings on coronary angiography. Also, as observed in the patients with coronary artery diseases, elevated CRP levels in CSX patients were shown to be independent from age, gender, obesity and cholesterol levels, which suggested that inflammation may enhance effect of certain conventional risk factors on promoting endothelial dysfunction and atherogenesis [3].

As reported previously [24], prevalence of $H$. pylori infection in CSX patients was significantly higher than normal controls ; however, there was no significant difference in the prevalence of anti-CagA+ between two groups. The patients with CSX were detected 
to have significantly higher plasma hs-CRP levels in comparison with normal controls. Also in both groups, plasma levels of hs-CRP in anti-H. pylori+ and anti-CagA+ subjects were higher than those in anti-H. pylori- and anti-CagA- ones, respectively.

Regarding the present results, it could be speculated that $H$. pylori and prominently its $\mathrm{Cag} A+$ strain infection can cause chronic inflammation and increase generation of various inflammatory metabolites including hs-CRP. Probably, this involves the whole atherogenic process, facilitates everything from the initial recruitment of leukocytes to the vessel walls that may affect vessel motility and elicits inflammatory and proliferative changes in vessel walls, leading to endothelial dysfunction as the most prominent cause of CSX.

\section{Conclusion}

In conclusion, it is hypothesized that $H$. pylori infection and prominently $\mathrm{Cag} \mathrm{A}+\mathrm{can}$ be a trigger for the probable mechanism of endothelial dysfunction via increasing levels of hsCRP in the pathogenesis of CSX. Since endothelial dysfunction is the trigger point for many diseases, more attention is to be paid to diagnosis and treatment of $H$. pylori. As far as H. pylori is concerned, it may be the cause of (or at least one of the leading factors in) many other diseases. To address this hypothesis, it is necessary to perform more prospective studies for evaluating role of $H$. pylori eradication on endothelial function.

\section{Acknowledgment}

This work is derived from a Master of Science thesis in biochemistry and supported by research grant from the Urmia University of Medical Sciences, Urmia, Iran.

\section{References}

1. T. Hurst, T. H. Olson, L. E. Olson, and C. P. Appleton, Am. J. Medicine 119, 560 (2006). http://dx.doi.org/10.1016/j.amjmed.2005.07.009

2. Y. Rasmi and S. Raeisi, Cardiol. J. 16, 585 (2009).

3. A. Espliguero, N. Mollichelli, P. Avanzas, E. Zouridakis, V. R. Newey, D. K. Nassiri, and J. C. Kaski, Eur. Heart J. 24, 2006 (2003). http://dx.doi.org/10.1016/j.ehj.2003.09.029

4. G. A. Lanza, Heart 93, 159 (2007). http://dx.doi.org/10.1136/hrt.2005.067330

5. J. Cosin-Sales, C. Pizzi, S. Brown, and J. C. Kaski, J. Am. Coll. Cardiol. 41, 1468 (2003). http://dx.doi.org/10.1016/S0735-1097(03)00243-2

6. T. Nyandak, A. Gogna, S. Bansal, and M. Deb, JIACM 8, 217 (2007).

7. M. B. Clearfield, J. Am. Osteopath. Assoc. 105, 409, (2005).

8. S. A. Sakr, T. M. Abbas, M. Z. Amer, E. M. Dawood, N. El-Shahat, I. A. A. Aal, and M. M. Ramadan, Int. Heart J. 50, 407 (2009) .http://dx.doi.org/10.1536/ihj.50.407

9. A. Gasbarrini, F. Franceschi, A. Armuzzi, V. Ojetti, M. Candelli, E. S. Torre, A. D. Lorenzo, M. Anti, S. Pretolani, and G. Gasbarrini, Gut 45, I9 (1999). http://dx.doi.org/10.1136/gut.45.2008.i9

10. T. Oshima, R. Ozono, Y. Yano, Y. Oishi, H. Teragawa, Y. Higashi, M. Yoshizumi, and M. Kambe, J. Am. Coll. Cardiol. 45, 1219 (2005). http://dx.doi.org/10.1016/j.jacc.2005.01.019 
11. M. Mayr, S. Kiechl, M. A. Mendall, J. Willeit, G. Wick, and Q. Xu, Stroke 34, 610 (2003). http://dx.doi.org/10.1161/01.STR.0000058481.82639.EF

12. B. Huang, Y. Chen, Q. Xie, G. Lin, Y. Wu, Y. Feng, J. Li, Y. Zhuo, and P. Zhang, Dig. Dis. Sci. 56, 109, (2011). http://dx.doi.org/10.1007/s10620-010-1274-6

13. Y. Rasmi, S. Raeisi, and M. H. S. Mohammadzad, Helicobacter 17, 116 (2012). http://dx.doi.org/10.1111/j.1523-5378.2011.00923.x

14. R. Eskandarian, M. Malek, S. H. Mousavi, and M. Babaei, Med. J. 47, 704 (2006).

15. O. F. Karatas, O. Bayrak, E. Cimentepe, and D. Unal, Med. Hypotheses 69, 963 (2007). http://dx.doi.org/10.1016/j.mehy.2007.01.030

16. I. Sbarsi, C. Falcone, C. Boiocchi, I. Campo, M. Zorzetto, A. D. Silvestri, and M. Cuccia, Int. J. Immunopathol. Pharmacol. 20145 (2007).

17. E. Anuurad, R. P. Tracy, T. A. Pearson, K. Kim, and L. Berglund, Atherosclerosis 205, 290, (2009). http://dx.doi.org/10.1016/j.atherosclerosis.2008.11.028

18. R.A. Lobo, Menopause 15, 1036 (2008). http://dx.doi.org/10.1097/gme.0b013e318184c45a

19. P. Tondi, A. Santoliquido, A. D. Giorgio, A. Sestito, G. A. Sgueglia, R. Flore, G. Careri, G. Pinnacchio, G. A. Lanza, and F. Crea, Eur. Rev. Med. Pharmacol. Sci. 15, 1074 (2011).

20. D. I. Buckley, R. Fu, M. Freeman, K. Rogers, M. Helfand, Ann. Intern. Med. 151, 483 (2009). http://dx.doi.org/10.7326/0003-4819-151-7-200910060-00009

21. P. Calabro, E. Golia ,E. T. Yeh, Semin. Immunopathol. 31, 79 (2009). http://dx.doi.org/10.1007/s00281-009-0149-4

22. P. Ong, R. Sivanathan, G. Borgulya, M. Bizrah, Y. Iqbal, J. Andoh, D. Gaze, and J. C. Kaski, Cardiovasc. Drugs Ther. 26, 239 (2012). http://dx.doi.org/10.1007/s10557-012-6382-4

23. A. Recio-Mayoral, O. E. Rimoldi, P. G. Camici, and J. C. Kaski, JACC Cardiovasc. Imaging 6 (6), 660 (2013). http://dx.doi.org/10.1016/j.jcmg.2012.12.011 PMid:23643286

24. Y. Rasmi, M. H. S. Mohammadzad, J. Cardiovasc. Dis. Res. 3, 19 (2012). http://dx.doi.org/10.4103/0975-3583.91597 